\title{
Incidência de huanglongbing (greening) em áreas de citros no município de Espírito Santo do Turvo, SP
}

\author{
Tais Santo Dadazio ${ }^{1}$, Roque Carvalho Dias ${ }^{1}$, Clóvis Machado², Ivana Paula Ferraz Santos Brito \\ Ana Karollyna Alves Matos ${ }^{1} \&$ Evelize de Fátima Saraiva David ${ }^{2}$
}

\section{RESUMO}

O huanglongbing (HLB) ou greening é atualmente considerada a doença mais importante e destrutiva da citricultura mundial. Sendo o Brasil um grande produtor, o HLB prejudica e coloca em risco toda a cadeia produtiva da cultura no país, gerando perdas expressivas. A queda de frutos sintomáticos e redução da qualidade e produtividade são os principais impactos causados pelo patógeno. A capacidade de dispersão do inseto vetor, o psilídeo Diaphorina citri, entre áreas periféricas (bordaduras), além do poder de disseminação do patógeno por insetos desenvolvidos em plantas contaminadas torna o manejo de controle da doença, difícil. Assim, o presente trabalho teve como objetivo avaliar os índices de HLB, em área total da propriedade. O estudo foi realizado no município de Espírito Santo do Turvo, SP, em uma propriedade com atividade comercial. Foram realizadas inspeções visuais e quantificação de plantas sintomáticas, por meio de inspeções realizadas por equipes em plataformas. Os dados obtidos foram submetidos à análise estatística descritiva, e avaliados quanto à frequência de ocorrência da doença. Os resultados demonstraram que a incidência na distribuição espacial do HLB se concentrou na região periférica da fazenda, em comparação com áreas centrais dos talhões, que apresentaram incidência próxima a zero.

Termos de indexação: bordadura, Citrus sinensis, HLB.

\section{Huanglongbing (greening) incidences in citrus areas in the municipality Espírito Santo do Turvo, SP}

\section{SUMMARY}

The Huanglongbing (HLB) or greening is currently considered the most important and destructive disease of citrus worldwide. Brazil is a largest producer of citrus, HLB undermines and endangers the entire productive chain of culture in the country, generating significant losses. The fall of symptomatic fruit and reduction of quality and productivity arethe main impact of the pathogen. The vector insect dispersal capacity, the psyllid Diaphorina citri, from peripheral areas (borders), beyond the power of dissemination of the pathogen by insects developed in plants contaminated makes management difficult to control. This work aimed to evaluate the contents of HLB, in total area of the property. The study was conducted in the municipality of Espírito Santo do Turvo, SP in a property with commercial activity. It is made visual inspection and quantification of symptomatic

${ }^{1}$ Faculdade de Ciências Agronômicas, Universidade Estadual Paulista - UNESP, Botucatu, SP, Brasil

${ }^{2}$ Faculdades Integradas de Bauru - FIB, Bauru, SP, Brasil 
plants by means of inspections conducted by staff on platforms. The data were submitted to descriptive statistical analysis, and evaluated for the frequency of occurrence of the disease. The results showed that the incidence spatial distribution of HLB concentrated in the peripheral region of the farm also called boundary compared to the central areas of the blocks which showed close to zero incidence.

Index terms: surrounds, Citrus sinensis L., HLB.

\section{INTRODUÇÃO}

O Brasil um dos grandes produtores de citricultura do mundo tem produção estimada para a safra 2017/2018 de 364,4 milhões de caixas de 40,8 kg (CitrusBR, 2017), sendo o estado de São Paulo o principal responsável pela produção nacional (FUNDECITRUS, 2017).

Na mesma velocidade em que a citricultura brasileira se desenvolveu e expandiu, surgiram inúmeras pragas e doenças, algumas causando danos diretos e outros indiretos, por serem insetos vetores de fitopatógenos (Parra et al., 2003; Gravena, 2005). Dentre as doenças, a de maior impacto econômico é o huanglongbing (HLB) ou greening, causada pela bactéria Candidatus Liberibacter spp. e considerada a mais importante para a indústria citrícola mundial (Bové, 2006).

Os primeiros sintomas do HLB no país foram observados em março de 2004, em pomares localizados na região de Araraquara - SP. Os sintomas verificados foram associados a duas espécies de bactérias a Candidatus Liberibacter asiaticus e a $C a$. Liberibacter americanus, (Coletta-Filho et al., 2004; Teixeira et al., 2005), transmitidas naturalmente no campo por meio do psilídeo asiático dos citros, Diaphorina citri Kuwayama (Lopes et al., 2009).

D. citris e destaca por sua rápida disseminação nos pomares (Fernandes, 2004) e ampla gama de hospedeiros do gênero Citrus e relacionados, com destaque para Murraya spp. (Lopes et al., 2006).

Quando o psilídeo infectivo migra de um pomar para outro, ele tende a se concentrar em plantas próximas à periferia, causando o chamado efeito de borda, sendo essa uma característica marcante do HLB (Bassanezi et al., 2005; Gottwald et al., 2008).

Para o manejo de HLB a inspeção é de suma importância, visando à identificação das plantas doentes e erradicação da fonte de inóculo. No Estado de São Paulo, as inspeções comumente são realizadas nas propriedades por inspetores caminhando a pé ao lado das plantas e em plataformas de inspeção acopladas em tratores.

Os principais métodos para controle são o uso de mudas sadias, eliminação do inóculo por meio da erradicação de plantas doentes, e controle do inseto vetor. O controle exige inspeções periódicas, com intervalos de no máximo quatro meses, para detecção e eliminação imediata de todas as plantas identificadas com sintomas (Belasque Junior et al., 2010). Como discutido por Bové (2006) e Gottwald et al. (2007) o conhecimento da proporção de plantas sintomáticas e assintomáticas é importante e deve ser utilizado na decisão da eliminação de pomares altamente infestados.

Com base no exposto, o objetivo do presente trabalho foi avaliar a incidência e comportamento do HLB em propriedade comercial no Município de Espírito Santo do Turvo, São Paulo.

\section{MATERIAL E MÉTODOS}

\section{Caracterização da área experimental}

O experimento foi realizado no período de 01 de janeiro a 30 de setembro de 2016, em uma propriedade comercial de citros, unidade Rensi da empresa Agroterenas S/A Citrus, localizada no sul do parque citrícola paulista, no município de Espírito Santo do Turvo no Estado de São Paulo. A Unidade Rensi possui 2.390,34 hectares plantados, com total de 1.198 .111 plantas, com média de 501 plantas/hectare. Esta região possui baixa incidência de HLB quando comparada com outras regiões tradicionais na produção citrícola.

A área é dividida em diferentes zonas, e estas subdivididas em talhões, com dimensões variadas de acordo com topografia da área, a fim de favorecer o manejo e a logística de escoamento da produção (Figura 1).

Além disso, em cada zona, a quantidade de talhões é variável de acordo com o tamanho da mesma, e estas apresentam o plantio de uma ou mais variedades, como pode ser visto na Tabela 1. A idade das plantas varia de 7 aos 10 anos, o que influencia diretamente na produção. 


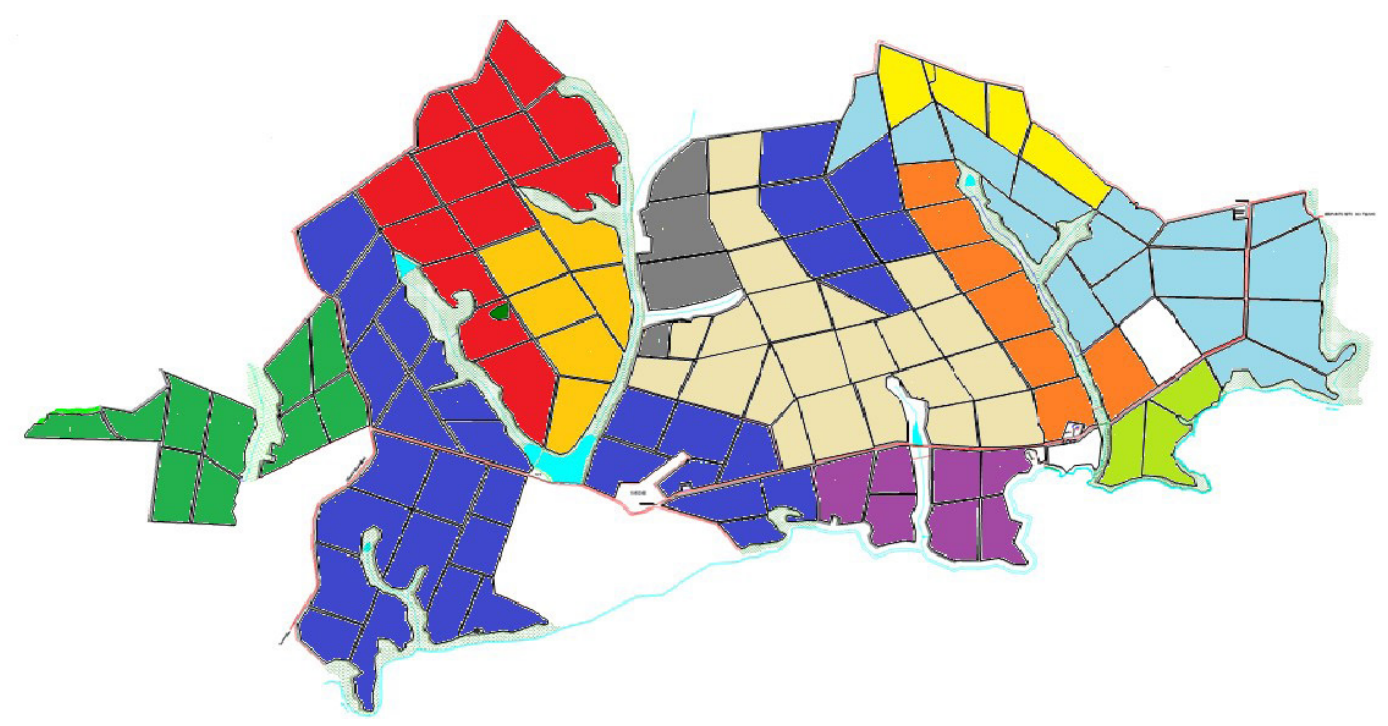

Figura 1. Croqui da área de produção de laranja doce da unidade Rensi (Agroterenas S/A) localizada no município de Espírito Santo do Turvo, Estado de São Paulo, com a identificação da divisão em onze zonas ilustradas pelas diferentes cores.

Tabela 1. Caracterização das zonas e pomares da unidade experimental estudada no município de Espírito Santo do Turvo, SP

\begin{tabular}{cccrccc}
\hline Zona & Talhões & Área (ha) & Plantas & Porta enxerto & Variedade & $\begin{array}{c}\text { Idade } \\
\text { (Anos) }\end{array}$ \\
\hline $\mathbf{4 0 1}$ & 07 & 117,97 & 48.627 & Swingle & Hamilim & 10 \\
$\mathbf{4 0 2}$ & 18 & 289,70 & 129.447 & Swing/Cleópatra & Natal/Rubi & 9,9 \\
$\mathbf{4 0 3}$ & 34 & 590,48 & 280.703 & Cleópatra/Sunki/Swing & Pêra/Natal/Rubi & 9,9 \\
$\mathbf{4 0 4}$ & 04 & 65,62 & 37.021 & Swingle & Folha murcha/Natal & 8 \\
$\mathbf{4 0 5}$ & 15 & 252,36 & 116.494 & Swing/Cleopatra & Valência/Natal & 9,9 \\
$\mathbf{4 0 6}$ & 02 & 42,44 & 17.788 & Swingle & Hamilim & 10 \\
$\mathbf{4 0 8}$ & 06 & 106,84 & 50.190 & Swinggle & Natal & 10 \\
$\mathbf{4 1 0}$ & 10 & 144,07 & 84.293 & Sunki/Cravo/Cleópatra & Pêra & 8,9 \\
$\mathbf{4 1 4}$ & 04 & 76,69 & 43.768 & Cleópatra & Pêra & 7 \\
$\mathbf{4 1 5}$ & 21 & 321,13 & 187.187 & Sunki & Pêra & 7 \\
$\mathbf{4 1 6}$ & 08 & 100,12 & 58.789 & Volkamericano & Rubi & 7 \\
\hline
\end{tabular}

\section{Coleta de informações e avaliações}

Para a seleção dos talhões experimentais foram usados os estudos de distribuição espacial da doença nos pomares utilizando-se os mapas de erradicação de plantas com sintomas de HLB dos últimos anos, priorizando-se as áreas mais críticas, ou seja, com maior incidência de HLB. Foram nesses talhões selecionados que se iniciaram os trabalhos de inspeção em plataforma. A escolha dos talhões seguiu programação baseada em safras anteriores, de acordo com nível de erradicação. Iniciou-se pelas zonas/talhões mais críticos da fazenda, zonas periféricas ou centrais, com foco no manejo fitossanitário, com intuito de manter nível de controle ou prevenir a disseminação da doença na área.

Para os trabalhos de inspeção utilizou-se plataformas de inspeção onde duas pessoas com atribuição profissional em inspeção de HLB e cancro cítrico se alocam na parte superior, para verificar a presença da doença nos pomares, e duas na parte inferior, munidas de motosserra, para 
erradicação das plantas doentes (Figura 2). A velocidade de deslocamento da plataforma foi de $2 \mathrm{~km} \mathrm{~h}^{-1}$, com rendimento operacional 900 a 1.000 plantas pessoa dia $^{-1}$. Para cada 205.000 plantas (401 hectares), foi utilizada uma plataforma, e o caminhamento das equipes de inspeção foi realizado em linhas paralelas (Figura 3). Ao encontrar plantas doentes, essas foram imediatamente cortadas utilizando-se de motosserra.

Os dados referentes ao número de plantas sintomáticas, foram anotados em planilha mediante o acompanhamento em solo das equipes de inspeção, onde cada plataforma realizou inspeção individual das plantas do talhão, e ao término determinou-se o total de plantas sintomáticas erradicadas.

\section{Análise estatística}

Os dados obtidos foram submetidos à análise estatística descritiva, e avaliados quanto à frequência de ocorrência da doença, comparando-os ao levantamento de 2015, realizado pela propriedade.

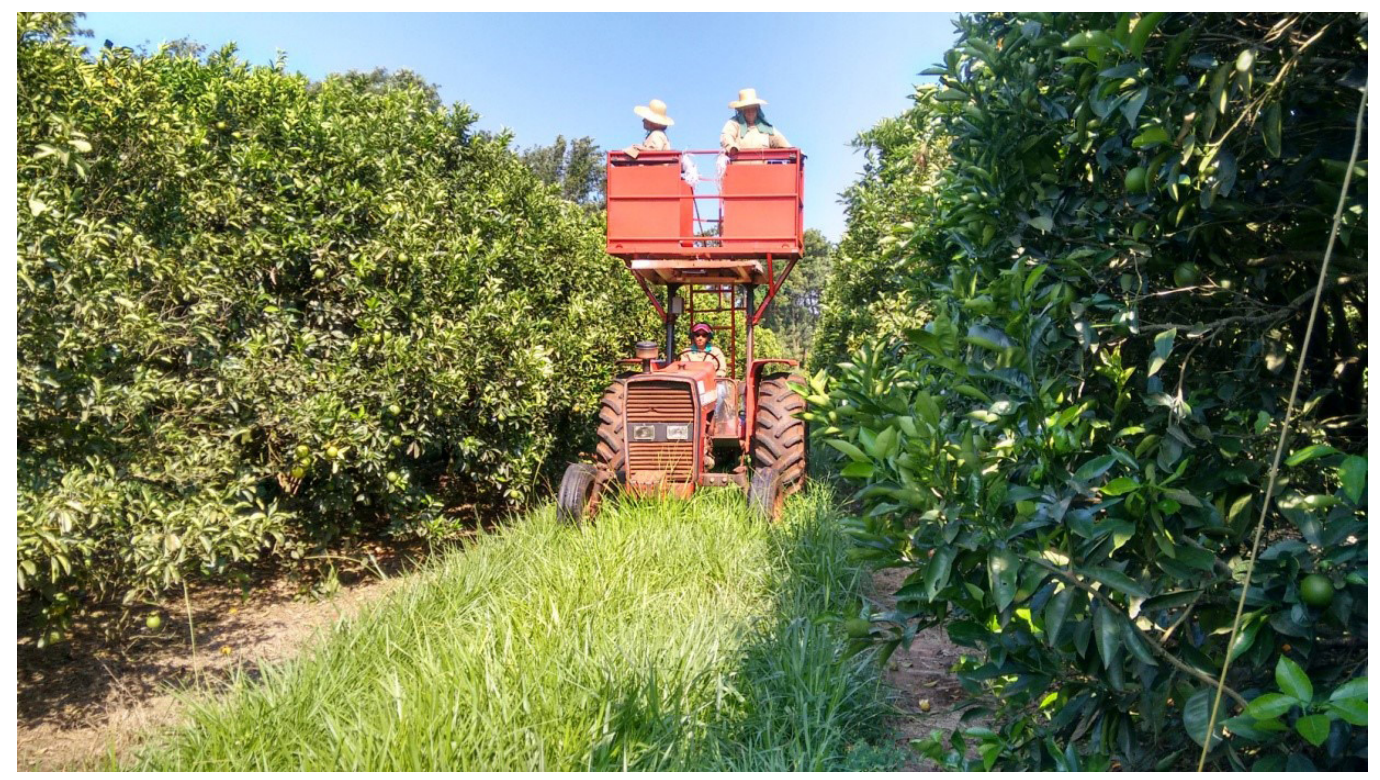

Figura 2. Método de inspeção com plataforma realizado na unidade Rensi (Agroterenas S/A).

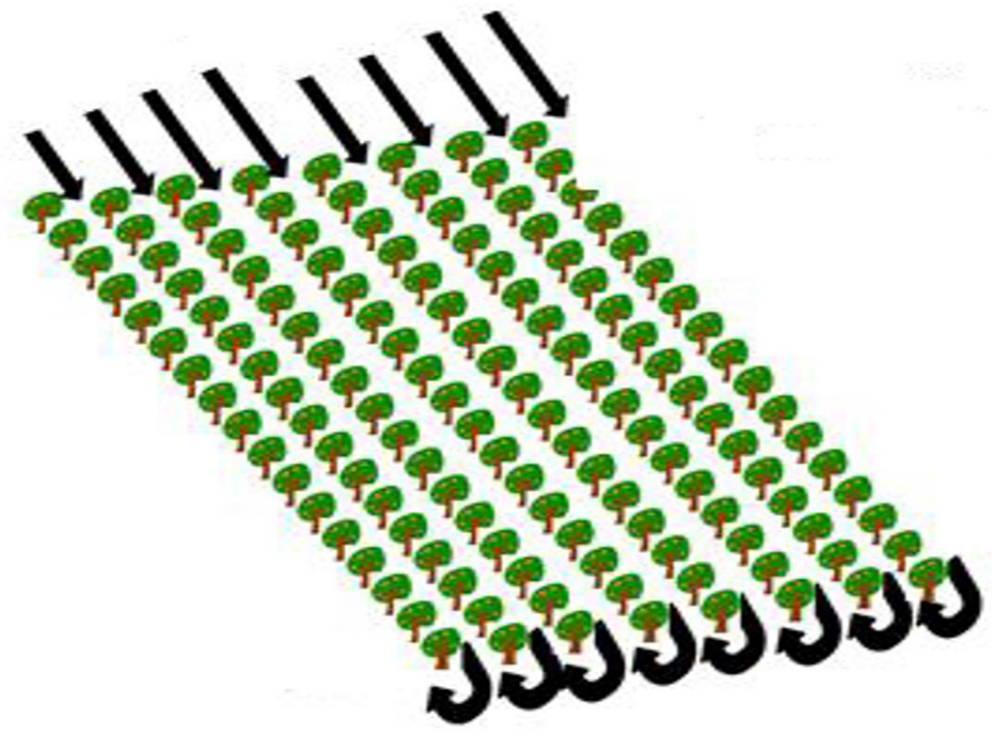

Figura 3. Sentido de caminhamento da equipe de inspeção. 


\section{RESULTADOS E DISCUSSÃO}

Segundo o levantamento amostral realizado na Fazenda Rensi, a incidência de HLB variou de 0 a 2,74\% entre as zonas avaliadas. As maiores incidências foram relatadas nas zonas 405 (2,74\%), 404 (2,31-2,33\%) e 416 (2,04\%) que correspondem, respectivamente à 964, 3235 e 1111 plantas infectadas por HLB (Tabela 2).

Comparando-se esses resultados com os obtidos em levantamentos realizados no ano 2015 , foi possível observar redução no número de plantas infectadas nas zonas 405 e 416, que continham, em 2015, 2633 e 2239 plantas infectadas, respectivamente.

A zona 404, localizada em região periférica (bordadura) da fazenda, ao contrário das anteriores, apresentou ampliação na incidência de plantas com HLB. Em 2015 os dados apontaram a presença de 655 plantas infectadas, número menor que o verificado no levantamento realizado em 2016, de 3235 plantas com HLB.

Isto deve-se a um padrão espacial, em que a maior parte das plantas sintomáticas são observadas na periferia, tanto em relação ao talhão como também à propriedade (Gottwald et al., 1989; Bassanezi et al., 2005). Além disso, taxas maiores de infecção de HLB tendem a ser observadas na interface do plantio de citrus com áreas sem citrus, não apenas no perímetro do pomar, mas, também, em espaços internos da plantação criados por carreadores, canais, represas, matas, galpões de máquinas, e sedes (Gottwald et al., 2008).

Constatou-se incidências médias de HLB nas zonas $402(1,72-1,77 \%), 403(1,74-0,76 \%)$ e $410(1,47 \%)$, correspondendo a 2377,4947 e 2415 plantas infectadas, respectivamente. Em relação ao levantamento de 2015, a taxa de incidência não apresentou grandes alterações, sendo anteriormente verificadas 3501, 4717 e 2404 plantas infectadas, respectivamente.

Esses dados corroboram com o verificado pela FUNDECITRUS (2017), que demonstrou que os níveis de infecção de HLB se manteve estável em relação ao ano de 2015 no estado de São Paulo. Os dados apontaram que no ano de 2016 16,92\% das laranjeiras (332,5 milhões de árvores) estavam contaminadas com a doença, sendo esse índice, praticamente igual ao do ano de 2015, de 17,89\%.

A ausência de plantas sintomáticas nas zonas 401, 406, 408, 414 e 415, e em plantas da variedade Rubida zona 403, pode ser explicada pelo manejo fitossanitário com inspeções periódicas, em torno de 20 a 25 dias, e as constantes pulverizações a fim de controlar o vetor da bactéria, o psilídeo Diaphorina citri. Com isso também, de acordo com Monteiro et al. (2013), passam a ser observadas maiores concentrações de plantas doentes com HLB nas bordas, e menores incidências nas áreas centrais dos pomares.

Tabela 2. Plantas de laranjas doce com sintomas de HLB nas zonas da Fazenda Rensi (Espírito Santo do Turvo, SP) no levantamento realizado no ano de 2016

\begin{tabular}{cccc}
\hline Zona & Variedade & População de plantas & Plantas com HLB (\%) \\
\hline $\mathbf{4 0 1}$ & Hamlim & 57.144 & 0,00 \\
$\mathbf{4 0 2}$ & Natal & 128.929 & 1,72 \\
& Rubi & 8.742 & 1,77 \\
$\mathbf{4 0 3}$ & Pêra & 275.125 & 1,74 \\
& Natal & 13.479 & 0,76 \\
& Rubi & 7.139 & 0,00 \\
$\mathbf{4 0 4}$ & Folha Murcha & 23.019 & 2,31 \\
& Natal & 18.595 & 2,33 \\
$\mathbf{4 0 5}$ & Valência & 113.285 & 2,74 \\
& Natal & 26.76 & 0,49 \\
$\mathbf{4 0 6}$ & Hamlim & 26.395 & 0,00 \\
$\mathbf{4 0 8}$ & Natal & 45.222 & 0,00 \\
$\mathbf{4 1 0}$ & Pêra & 164.641 & 1,47 \\
$\mathbf{4 1 4}$ & Pêra & 40.082 & 0,00 \\
$\mathbf{4 1 5}$ & Pêra & 167.066 & 0,00 \\
$\mathbf{4 1 6}$ & Rubi & 54.363 & 2,04 \\
\hline
\end{tabular}




\section{CONCLUSÕES}

A incidência na distribuição espacial do HLB se concentrou na região periférica da fazenda, em comparação com áreas centrais dos talhões, que apresentaram incidência próxima a zero.

\section{REFERÊNCIAS}

Associação Nacional dos Exportadores de Sucos Cítricos - CitrusBR. (2017). Produção de laranja e suco. São Paulo. Recuperado em 18 de junho de 2017, de http:// www.citrusbr.com/destaques/?id=312425

Bassanezi, R. B., Busato, L. A., Bergamin Filho, A., Amorim, L., \& Gottwald, T. (2005). Preliminary spatial pattern analysis of huanglongbing in São Paulo, Brazil. In M. E. Hilf, N. Duran-Vila, \& M. A. Rocha-Peña (Eds.), Proceedings of the 16th Conference of the International Organization Citrus Virologist (p. 341-355). Riverside: IOCV.

Belasque Junior, J., Barbosa, J. C., Bergamin Filho, A., \& Massari, C. A. (2010). Prováveis consequências do abrandamento da metodologia de erradicação do cancro cítrico no Estado de São Paulo. Tropical Plant Pathology, 35(5), 314-317. http://dx.doi.org/10.1590/ S1982-56762010000500007.

Bové, J. M. (2006). Huanglongbing: a destructive, newlyemerging, century-old disease of citrus. Journal of Plant Pathology, 88(1), 7-37.

Coletta-Filho, H. D., Targon, M. L. P. N., Takita, M. A., De Negri, J. D., Pompeu Junior, J., Machado, M. A., Amaral, A. M., \& Muller, G. W. (2004). First report of the causal agent of huanglongbing ("Candidatus Liberibacter asiaticus") in Brazil. Plant Disease, 88(12), 1382. http:// dx.doi.org/10.1094/PDIS.2004.88.12.1382C.

Fernandes, N. G. (2004). Combate ao greening em citros necessita de legislação específica. Visão Agrícola, 1(2), 40-42.

Fundo de Defesa da Citricultura - FUNDECITRUS. (2017). Previsão de safra 2017/2018. Araraquara. Recuperado em 19 de junho de 2017, de http:/www.fundecitrus.com.br/ pdf/pes_relatorios/2017_12_05_Invent $\%$ C $3 \%$ A 1rio_e_ Estimativa_do_Cinturao_Citricola_2017-2018.pdf

Gottwald, T. R., Graça, J. V., \& Bassanezi, R. B. (2007). Citrus Huanglongbing: the pathogen and its impact. Plant Health Progress, 9.
Gottwald, T. R., Irey, M., Bergamin Filho, A., Bassanezi, R. B., \& Gilligan, C. (2008). A stochastic spatiotempoal analysis of the contribution of primary versus secondary spread of HLB. In Proceedings of the International Research Conference on Huanglongbing (p. 285-290). Orlando: IRCH.

Gottwald, T. R., Timmer, L. W., \& McGuire, R. G. (1989). Analysis of disease progress of citrus canker in nurseries in Argentina. Phytopathology, 79(11), 1276-1283.

Gravena, S. (2005). Manual prático de manejo ecológico de pragas dos citros (372 pp.). Jaboticabal: Gravena.

Lopes, S. A., Bertolini, E., Frare, G. F., Martins, E. C., Wulff, N. A., Teixeira, D. C., Fernandes, N. G., \& Cambra, M. (2009). Graft transmission efficiencies and multiplication of 'Candidatus Liberibacter americanus' and ' $C a$. Liberibacter asiaticus' in citrus plants. Phytopathology, 99(3), 301-306. http://dx.doi.org/10.1094/PHYTO-99-30301. PMid:19203283.

Lopes, S. A., Martin, E. C., \& Frare, G. F. (2006). Detecção de Candidatus Liberibacter asiaticus em Murraya paniculata. Fitopatologia Brasileira, 31, 303.

Monteiro, A. B. (2013). Efeito de um pomar sem manejo de Huanglongbing sobre a ocorrência de Diaphorina citri e incidência de plantas doentes em uma área vizinha com manejo da doença. Araraquara: Fundo de Defesa da Citricultura.

Parra, J. R. P., Oliveira, H. N., \& Pinto, A. S. (2003). Guia ilustrado de pragas e insetos benéficos dos citros (140 pp.). Piracicaba: FEALQ.

Teixeira, D. C., Luc Danet, J., Eveillard, S., Cristina Martins, E., Jesus Junior, W. C., Yamamoto, P. T., Lopes, S. A., Bassanezi, R. B., Ayres, A. J., Saillard, C., \& Bové, J. M. (2005). Citrus hanglongbing in São Paulo State, Brazil: PCR detection of the 'Candidatus Liberibacter' species associated with the disease. Molecular and Cellular Probes, 19(3), 173-179. http://dx.doi.org/10.1016/j. mcp.2004.11.002. PMid:15797817.

Recebido: Março 17, 2017

Aceito: Setembro 19, 2017

Como citar: Dadazio, T. S., Dias, R. C., Machado, C., Brito, I. P. F. S., Matos, A. K. A., \& David, E. F. S. (2018). Incidência de Huanglongbing (Greening) em áreas de citrus no município de Espírito Santo do Turvo, SP. Citrus Research and Technology, 39, e-1032. http://dx.doi.org/10.4322/crt.0126 